\title{
Relationship between sensitivity to carbon dioxide and clinical features in patients with chronic airways obstruction
}

\author{
D. J. LA NE ${ }^{1}$ and J.B. L. HOWE L L ${ }^{2}$ \\ The University Department of Medicine, Manchester Royal Infirmary, Manchester
}

\begin{abstract}
This study was designed to investigate the relationship between the different clinical features exhibited by patients with chronic airways obstruction and their responsiveness to carbon dioxide. In 19 patients pulmonary function was assessed by spirometry, lung volumes and arterial blood gases. Measurements of responsiveness to carbon dioxide were made and compared with responses obtained in five normal subjects. Assessed in terms of inspiratory mechanical work performed rather than ventilation achieved, it was shown that there was a highly significant positive correlation between work rate response and the level of dyspnoea, so that patients with poor response experienced little dyspnoea despite severe airways obstruction. Significant negative correlations were found between work rate response and the presence of oedema, polycythaemia and a raised resting arterial $\mathrm{CO}_{2}$ tension, and a positive correlation was found with radiographic evidence of emphysema. A reduced work rate response to $\mathrm{CO}_{2}$ was taken to signify diminished central sensitivity to carbon dioxide. The cause of the reduced sensitivity was not elucidated, but it was concluded that several of the clinical features associated with chronic airways obstruction were related to loss of $\mathrm{CO}_{2}$ sensitivity.
\end{abstract}

Patients with chronic airways obstruction present a variety of clinical features. Baldwin, Cournand, and Richards (1949) recognized four groups, representing progressive degrees of abnormality of the blood gases. Congestive cardiac failure was seen only in the most severely affected group, and it later became evident that these patients experienced rather less dyspnoea than others with more normal blood gases (Richards, 1960).

Subsequent studies of pulmonary function and pathology have led to a more detailed characterization of differences between patients. The picture which has emerged is of two contrasting extremes generally called emphysematous and bronchitic (Fletcher, Hugh-Jones, McNicol, and Pride, 1963; Mitchell and Filley, 1964) but also called fighters and non-fighters (Robin and O'Neill, 1963) or 'pink and puffing' and 'blue and bloated' (Scadding, 1963). The emphysematous group are characterized clinically by the presence of severe dyspnoea. Often they produce only a little mucoid sputum and tend to be underweight. Right ventricular hypertrophy and polycythaemia are

1Address for reprints: Nuffield Department of Medicine, The Radcliffe Infirmary, Oxford

2Present address: Department of Medicine, Southampton University not seen. Respiratory failure with reduced oxygen saturation and raised carbon dioxide tension $\left(\mathrm{PCO}_{2}\right)$ and congestive cardiac failure occur only terminally. Those patients with clear radiological and post-mortem evidence of emphysema, especially of the panacinar type, fall into this group (Kahana, Aronovitch, and Place, 1963 ; Burrows, Fletcher, Heard, Jones, and Wootliff, 1966), these findings being associated with an increased total lung capacity (Fletcher et al., 1963) and reduced diffusing capacity (Ogilvie, 1959). Nitrogen washout techniques (Briscoe and Nash, 1965) reveal an excessively large 'slow space' which has a poor ventilation/perfusion ratio. Although resting arterial oxygen tension $\left(\mathrm{PaO}_{2}\right)$ is not greatly reduced, it falls significantly on exercise (Jones, 1966). Cardiac output is subnormal at rest and on exercise in this group, and systemic oxygen transport (product of total blood flow and arterial blood oxygen content) is also low (Filley, Beckwitt, Reeves, and Mitchell, 1968).

By contrast the bronchitic group are less troubled by dyspnoea. They often produce considerable quantities of mucopurulent sputum, tend to be overweight and may show radiological evidence of inflammatory changes in the lungs or 
bronchi. Blood gas tensions become deranged relatively early and there is a marked tendency for them to develop congestive cardiac failure with polycythaemia and electrocardiographic evidence of right ventricular hypertrophy. Radiological and post-mortem evidence of emphysema is less obvious and more often centrilobular in type and they have normal total lung capacity and diffusing capacity. The 'slow space', although increased, is smaller than in the emphysematous group but has more severe ventilation/perfusion disturbance. Resting arterial $\mathrm{PaO}_{2}$ is low but rises on exercise. Cardiac output is normal and systemic oxygen transport is better than in the emphysematous subjects.

Most workers recognize patients with intermediate features and it is apparent from clinical experience that there is no clear-cut separation of all patients into two groups. A few patients fit neatly into one category but many show some features of both. Furthermore, no satisfactory explanation has yet been offered for the difference between contrasting patients.

Common to all patients with airways obstruction is a reduced ventilatory responsiveness to $\mathrm{CO}_{2}$ (Reinhardt, 1912； Scott, 1920 ; Donald and Christie, 1949). Some workers attribute this chiefly to mechanical factors impeding ventilation (Richards, Fritts, and Davis, 1958; Brodovsky, Macdonell, and Cherniack, 1960) whilst others implicate reduced sensitivity of the respiratory centre to carbon dioxide (Prime and Westlake, 1954 ; Alexander, West, Wood, and Richards, 1955; Fishman, Samet, and Cournand, 1955; Park, 1965). Attempts to resolve these differences have produced conflicting results. It seemed possible that both of these mechanisms might be operative and that the relative importance of one or the other might be associated with differences in symptomatology. We have therefore investigated this problem in relation to the variable clinical features described above.

The drive from the respiratory centre was measured during rebreathing in terms of mechanical work performed and this, being independent of the degree of airways obstruction, was considered to be an index of $\mathrm{CO}_{2}$ sensitivity. The ventilation achieved for a given increment in mechanical work was taken as an index of impedance due to increased airways resistance (Richards et al., 1958). In this way it has been possible to show in any given patient whether reduced sensitivity or mechanical impedance, or both, are operative in reducing ventilatory response to $\mathrm{CO}_{2}$. Preliminary accounts of this work were given at a Symposium on Breathlessness at the University of Manchester (Howell and Campbell, 1966) and in a communication to the Physiological Society (Howell and Lane, 1969).

\section{METHODS}

PATIENTS Nineteen patients with chronic airways obstruction who were regularly attending the outpatient department and five normal subjects were studied. The patients were considered to be in a stable clinical and functional state. The signs, symptoms, and investigations considered to be important in the differentiation of emphysematous from bronchitic patients were recorded. Some of these could be quantified exactly, viz., arterial $\mathrm{CO}_{2}$ tension $\left(\mathrm{PaCO}_{2}\right)$, percentage oxygen saturation $\left(\mathrm{SaO}_{2}\right)$ and total lung capacity (TLC expressed as \% predicted) ; others were identified as present or absent, viz., oedema, polycythaemia (Hb $>20.0$ g. $/ 100 \mathrm{ml}$., PCV $>$ $56 \%$ ), right ventricular hypertrophy (ECG evidence) and emphysema (chest radiograph: Laws and Heard, 1962). The remainder were designated by some arbitrary index, viz., dyspnoea (M.R.C. classification, 1966) and sputum (usually mucopurulent 1, usually mucoid 0). No measurements were made of diffusing capacity, inert gas mixing efficiency, response to exercise or cardiac output.

Comparisons between these clinical features and $\mathrm{CO}_{2}$ response curves were made by the Student's $t$ test in those instances where two divisions (e.g., present or absent) were made (oedema, right ventricular hypertrophy, polycythaemia, sputum mucopurulence and emphysema): where three grades were recognized (dyspnoea), comparison between the grades was also made by the Student's $t$ test. In other instances where a continuous variable was being assessed the coefficient of simple correlation was calculated (TLC, $\mathrm{PaCO}_{2}, \mathrm{SaO}_{2}$ ).

TECHNIQUES Routine spirometry was performed with a Godart Pulmonet, functional residual capacity being measured by the helium dilution method. Arterial blood was withdrawn at rest from the brachial artery under anaerobic conditions and analysed for $p \mathrm{H}$ with an EIL electrode (or later a Radiometer electrode), for $\mathrm{PCO}_{2}$ with a Severinghaus electrode and for oxygen saturation with a Kipp haemoreflectometer.

Ventilation was measured in seated patients with a Godart pneumotachograph with integrator. Transpulmonary pressure recordings were taken between an intra-oesophageal balloon sited in the lower third of the oesophagus and the airway at the mouth and measured with an NEP capacitance manometer. Volume and pressure signals were fed into an $X Y$ recorder (Bryans Model 20170) where pressure/ volume loops were traced out for individual breaths. The area traced out by such a loop represented the work done against. viscous resistances during that 
breath. Joining points of no flow on the pressure/ volume loop gave the dynamic compliance line for the lungs which was used to divide the loop into inspiratory and expiratory phases. Work done against elastic resistances was calculated using the graphic representation of Campbell (1958) from the area between the dynamic compliance line of the lungs and the compliance line of the chest wall. The latter was obtained by subtraction of lung compliance from measurements of total compliance using the method of Cherniack and Brown (1965) or the relaxation pressure method (Rahn, Otis, Chadwick, and Fenn, 1946).

The rate of work done against viscous and elastic resistances in the lungs and elastic resistances within the chest wall during inspiration (inspiratory mechanical work rate) was measured as the index of $\mathrm{CO}_{2}$ responsiveness, since Milic-Emili and Tyler (1963) had shown that work done in expiration was not correlated with $\mathrm{CO}_{2}$ tension. A steady increase in $\mathrm{CO}_{2}$ stimulation was achieved by rebreathing from a 4-litre bag of $100 \%$ oxygen. Continuous recording of the $\mathrm{CO}_{2}$ level at the mouth was made during rebreathing by means of an infra-red analyser (Infra Red Development Co., Model DVB). After 60 to 90 seconds of rebreathing there was very little difference between the $\mathrm{CO}_{2}$ tension of inspired and expired gas, but for analysis purposes the maximal end-expiratory $\mathrm{CO}_{2}$ tension was taken for measurement. In four patients arterial samples were withdrawn from an indwelling cannula during rebreathing. Like Clark (1968) we found that, after the initial equilibration phase, arterial $\mathrm{CO}_{8}$ tension increased at the same rate as end-tidal $\mathrm{CO}_{2}$ tension but was at any instance some $2 \mathrm{~mm}$. $\mathrm{Hg}$ lower in absolute value. $\mathrm{CO}_{2}$ responsiveness was expressed graphically by plotting end- expiratory $\mathrm{CO}_{2}$ tension against simultaneously measured minute ventilation and inspiratory mechanical work rate. Plots obtained in this manner were curvilinear initially and then became linear. The slope of the most linear part of the curve was measured $\left(\mathrm{S}_{\mathrm{W}} \mathrm{I} / \mathrm{PCO}_{2}\right.$-inspiratory mechanical work rate response, $\mathrm{SV}_{\mathrm{E}} / \mathrm{PCO}_{2}$-ventilatory response). In addition plots of inspiratory mechanical work rate against ventilation were prepared. Strictly these should be drawn with ventilation, the dependent variable, as ordinate, but generally ventilation has been placed on the abscissa (Otis, 1964). The latter convention was therefore adopted here. These curves show a steadily increasing slope, and for comparative purposes the slope of the response over the ventilation range 8-18 $\mathrm{l} / \mathrm{min}$. was measured $\left(\mathrm{S} \dot{W} \mathrm{I} / \mathrm{V}_{E}\right)$.

\section{T A B L E I}

PHYSICAL CHARACTERISTICS AND SPIROMETRY OF

\begin{tabular}{|c|c|c|c|c|c|c|}
\hline Patient & Sex & $\begin{array}{c}\text { Age } \\
\text { (yrs) }\end{array}$ & $\underset{(\mathrm{cm} .)}{\mathrm{Ht}}$ & $\begin{array}{c}\text { Wt } \\
\text { (kg.) }\end{array}$ & $\begin{array}{l}\text { vC } \\
\text { (1.) }\end{array}$ & $\underset{(1 .)^{1 \cdot 0}}{\mathrm{FEV}_{1 \cdot 0}}$ \\
\hline $\begin{array}{l}\text { J.F. } \\
\text { M.H. } \\
\text { P.C.C. } \\
\text { M.P. } \\
\text { J.Br. } \\
\text { R.H. } \\
\text { J.N. } \\
\text { F.D. } \\
\text { H.R. } \\
\text { T.P.P. } \\
\text { S.R. } \\
\text { R.M. } \\
\text { L.M. } \\
\text { J.B. } \\
\text { C.C. } \\
\text { W.E. } \\
\text { A.S.S. } \\
\text { J.W. }\end{array}$ & $\begin{array}{l}\mathbf{M} \\
\mathbf{M} \\
\mathbf{M} \\
\mathbf{F} \\
\mathbf{M} \\
\mathbf{M} \\
\mathbf{M} \\
\mathbf{M} \\
\mathbf{M} \\
\mathbf{M} \\
\mathbf{M} \\
\mathbf{M} \\
\mathbf{M} \\
\mathbf{M} \\
\mathbf{M} \\
\mathbf{M} \\
\mathbf{M} \\
\mathbf{M} \\
\mathbf{M}\end{array}$ & $\begin{array}{l}39 \\
40 \\
45 \\
45 \\
47 \\
47 \\
54 \\
56 \\
58 \\
59 \\
59 \\
59 \\
60 \\
61 \\
64 \\
64 \\
64 \\
64 \\
74\end{array}$ & $\begin{array}{l}176 \\
180 \\
173 \\
147 \\
170 \\
178 \\
180 \\
178 \\
168 \\
178 \\
173 \\
175 \\
180 \\
158 \\
174 \\
163 \\
184 \\
171 \\
180\end{array}$ & $\begin{array}{l}66 \\
64 \\
65 \\
35 \\
68 \\
74 \\
69 \\
80 \\
70 \\
64 \\
67 \\
86 \\
63 \\
51 \\
67 \\
45 \\
70 \\
49 \\
69\end{array}$ & $\begin{array}{l}3.74 \\
2.66 \\
2 \cdot 13 \\
1.77 \\
2.86 \\
2.17 \\
3.96 \\
2.80 \\
1.71 \\
1.93 \\
2.07 \\
2.07 \\
2.67 \\
3.03 \\
2.08 \\
1.79 \\
3.93 \\
2.93 \\
2.89\end{array}$ & $\begin{array}{l}1.21 \\
0.74 \\
1.08 \\
0.38 \\
0.77 \\
0.70 \\
0.61 \\
0.83 \\
0.54 \\
0.79 \\
0.78 \\
0.79 \\
1.09 \\
0.68 \\
0.84 \\
0.76 \\
0.89 \\
0.65\end{array}$ \\
\hline
\end{tabular}

T A B L E I I

DATA ON BLOOU GASES, CLINICAL FEATURES, AND SLOPES OF RESPONSE CURVES

\begin{tabular}{|c|c|c|c|c|c|c|c|c|c|c|c|c|}
\hline$\underset{\text { tient }}{\text { Pa- }}$ & $\begin{array}{c}\text { Dys- } \\
\text { pnoea }\end{array}$ & Oedema & $\begin{array}{l}\text { Muco- } \\
\text { purul- } \\
\text { ence of } \\
\text { Sputum }\end{array}$ & $\begin{array}{l}\text { Polycy- } \\
\text { thaemia }\end{array}$ & $\begin{array}{c}\text { Right } \\
\text { Ventricu- } \\
\text { lar } \\
\text { Hyper- } \\
\text { trophy }\end{array}$ & $\begin{array}{c}\text { CXR } \\
\text { Evidence } \\
\text { of Em- } \\
\text { physema }\end{array}$ & $\begin{array}{c}\text { TLC \% } \% \\
\text { predicted }\end{array}$ & $\underset{\left(\mathrm{mm} . \mathrm{H}_{\mathrm{g}}\right)}{\mathrm{PaCO}_{\mathbf{g}}}$ & $\underset{(\%)}{\mathrm{SaO}_{2}}$ & $\begin{array}{l}\text { Slope } \\
\text { VE/PCo } \\
\text { (1./min/ } \\
\text { mm. Hg) }\end{array}$ & $\begin{array}{c}\text { Slope } \\
\text { W/ } / \text { Poo, } \\
\text { (kgm./ } \\
\text { min. } \\
\text { mm.Hg) }\end{array}$ & $\begin{array}{c}\text { Slope } \\
\dot{\mathbf{W}} / \mathbf{V E}_{\mathrm{E}} \\
\text { (kgm./1.) }\end{array}$ \\
\hline $\begin{array}{l}\text { J.F. } \\
\text { M.H. } \\
\text { P.C. } \\
\text { M.P. } \\
\text { J.Br. } \\
\text { R.H. } \\
\text { J.N. } \\
\text { F.D. } \\
\text { H.R. } \\
\text { T.P. } \\
\text { S.R. } \\
\text { S.S. } \\
\text { R.M. } \\
\text { L.R. } \\
\text { J.B. } \\
\text { C.C. } \\
\text { W.E. } \\
\text { A.S.S. } \\
\text { J.W. }\end{array}$ & $\begin{array}{l}1 \\
1 \\
1 \\
2 \\
3 \\
1 \\
2 \\
3 \\
3 \\
3 \\
3 \\
1 \\
2 \\
1 \\
2 \\
1 \\
3 \\
2 \\
3\end{array}$ & $\begin{array}{l}1 \\
1 \\
1 \\
1 \\
1 \\
1 \\
1 \\
1 \\
0 \\
1 \\
1 \\
1 \\
1 \\
0 \\
1 \\
1 \\
0 \\
0 \\
0\end{array}$ & $\begin{array}{l}1 \\
1 \\
0 \\
1 \\
1 \\
0 \\
0 \\
0 \\
0 \\
0 \\
1 \\
0 \\
0 \\
0 \\
1 \\
0 \\
0 \\
1 \\
0\end{array}$ & $\begin{array}{l}0 \\
1 \\
0 \\
0 \\
0 \\
0 \\
0 \\
0 \\
0 \\
0 \\
1 \\
1 \\
0 \\
0 \\
0 \\
0 \\
0 \\
1 \\
0\end{array}$ & $\begin{array}{l}1 \\
1 \\
0 \\
0 \\
0 \\
0 \\
0 \\
0 \\
0 \\
1 \\
0 \\
0 \\
0 \\
0 \\
1 \\
0 \\
0 \\
1 \\
0\end{array}$ & $\begin{array}{l}0 \\
0 \\
0 \\
1 \\
1 \\
0 \\
1 \\
1 \\
0 \\
0 \\
1 \\
0 \\
1 \\
0 \\
0 \\
0 \\
1 \\
0 \\
1\end{array}$ & $\begin{array}{r}120 \\
80 \\
93 \\
95 \\
135 \\
-104 \\
109 \\
117 \\
92 \\
105 \\
100 \\
126 \\
98 \\
103 \\
95 \\
124 \\
110 \\
74\end{array}$ & $\begin{array}{l}53 \\
63 \\
53 \\
57 \\
54 \\
65 \\
64 \\
41 \\
59 \\
46 \\
63 \\
61 \\
55 \\
38 \\
52 \\
57 \\
37 \\
50 \\
40\end{array}$ & $\begin{array}{l}84 \\
70 \\
90 \\
74 \\
80 \\
75 \\
89 \\
89 \\
88 \\
89 \\
79 \\
75 \\
96 \\
96 \\
82 \\
88 \\
90 \\
82 \\
76\end{array}$ & $\begin{array}{l}0.40 \\
0.46 \\
0.59 \\
0.22 \\
1.06 \\
0.77 \\
0.82 \\
0.58 \\
1.11 \\
0.34 \\
0.87 \\
0.31 \\
0.41 \\
0.95 \\
0.27 \\
0.34 \\
2.04 \\
0.47 \\
1.27\end{array}$ & $\begin{array}{l}0.07 \\
0.03 \\
0.11 \\
0.07 \\
0.24 \\
0.16 \\
0.14 \\
0.20 \\
0.25 \\
0.17 \\
0.12 \\
0.04 \\
0.10 \\
0.15 \\
0.07 \\
0.14 \\
0.45 \\
0.06 \\
0.24\end{array}$ & $\begin{array}{l}0.13 \\
0.11 \\
0.10 \\
0.29 \\
0.18 \\
0.18 \\
0.14 \\
0.28 \\
0.21 \\
0.20 \\
0.13 \\
0.10 \\
0.12 \\
0.15 \\
0.16 \\
0.11 \\
0.20 \\
0.10 \\
0.19\end{array}$ \\
\hline
\end{tabular}

In col. 2 the figures refer to the M.R.C. grading for dyspnoea.

In cols. 3 to 7,1 signifies present, 0 signifies absent. 
T A B L B II I

DATA ON NORMAL SUBJECTS

\begin{tabular}{|c|c|c|c|c|c|c|c|c|}
\hline Subject & $\begin{array}{l}\text { Age } \\
\text { (yrs) }\end{array}$ & $\underset{\text { (cm.) }}{\mathbf{H t}}$ & $\begin{array}{c}\text { Wt } \\
(\mathbf{k g .})\end{array}$ & $\begin{array}{l}\text { VC } \\
\text { (1.) }\end{array}$ & $\begin{array}{c}\mathrm{FEV}_{1 \cdot 0} \\
(\mathrm{l} .)\end{array}$ & $\begin{array}{c}\text { Slope } \\
\text { VE,'PCO, } \\
\text { (1./min./mm.Hg) }\end{array}$ & $\begin{array}{c}\text { Slope } \\
\dot{\text { Wil/PCO, }} \\
(\mathrm{kgm} . / \mathrm{min} . / \mathrm{mm} \\
\mathbf{H g})\end{array}$ & $\begin{array}{c}\text { Slope } \\
\text { Wr/Vz } \\
(\mathbf{k g m} \cdot / 1 .)\end{array}$ \\
\hline $\begin{array}{l}\text { B.C. } \\
\text { A.H. } \\
\text { J.H. } \\
\text { D.I. } \\
\text { T.R. }\end{array}$ & $\begin{array}{l}20 \\
32 \\
39 \\
32 \\
48\end{array}$ & $\begin{array}{l}170 \\
176 \\
187 \\
180 \\
165\end{array}$ & $\begin{array}{l}57 \\
72 \\
84 \\
70 \\
45\end{array}$ & $\begin{array}{l}4 \cdot 02 \\
4 \cdot 85 \\
6 \cdot 30 \\
5 \cdot 69 \\
3.94\end{array}$ & $\begin{array}{l}3.50 \\
3.95 \\
4.36 \\
4.97 \\
2.97\end{array}$ & $\begin{array}{l}3 \cdot 24 \\
3 \cdot 52 \\
2 \cdot 37 \\
2 \cdot 82 \\
1 \cdot 91\end{array}$ & $\begin{array}{l}0.42 \\
0.59 \\
0.51 \\
0.53 \\
0.33\end{array}$ & $\begin{array}{l}0.13 \\
0.12 \\
0.16 \\
0.14 \\
0.13\end{array}$ \\
\hline
\end{tabular}

\section{RESULTS}

The physical characteristics of the 18 male and 1 female patients studied are given in Table I, together with the results of routine pulmonary function tests and arterial blood analyses. The details of the clinical features are given in Table II, together with the values of the slopes of ventilatory and inspiratory mechanical work rate responses to $\mathrm{CO}_{2}$, and of the slopes of the curves relating ventilation to inspiratory mechanical work rate during $\mathrm{CO}_{2}$ stimulation. Data on the five normal subjects are given in Table III.

The mean slope of ventilatory responses to $\mathrm{CO}_{2}$ in the normal subjects was $2.77 \pm 0.691 . / \mathrm{min}$./

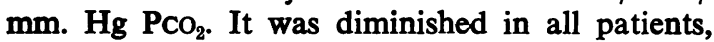
ranging from 0.22 to $2.04 \mathrm{l} / \mathrm{min}$. $/ \mathrm{mm}$. $\mathrm{Hg} \mathrm{PCO}_{2}$.

The mean slope of the inspiratory mechanical work rate response to $\mathrm{CO}_{2}$ in the normal subjects was $0.40 \pm 0.14 \mathrm{kgm} . / \mathrm{min} . / \mathrm{mm}$. $\mathrm{Hg} \mathrm{PCO}_{2}$. In some patients it was near normal; in others it was markedly diminished, the overall range being 0.03 to $0.45 \mathrm{kgm} . / \mathrm{min} . / \mathrm{mm}$. $\mathrm{Hg} \mathrm{PcO}_{2}$.

In 11 patients the relation between inspiratory mechanical work rate and ventilation fell within the normal range; in the remainder more work was performed to achieve a given ventilation than in the normal subjects.

Since the responses obtained are curvilinear, the differences between patients and normals cannot be completely described in terms of a slope from the most linear part of the curve, and therefore selected curves have been plotted in Figs 1, 2, and 3 , and compared with the range in normal subjects (shaded areas). In the three patients depicted in Fig. 1, inspiratory mechanical work rate response was near normal (Fig. 1, left). However, the ventilation achieved for a given increment in inspiratory mechanical work rate was less than normal (Fig. 1, right). Mechanical factors appeared to be dominant in reducing ventilatory response to $\mathrm{CO}_{2}$ in these patients. The three patients depicted in Fig. 2 showed a markedly diminished inspiratory mechanical work rate response to $\mathrm{CO}_{2}$ (Fig. 2, left), but the ventilation achieved for a given in- crement in inspiratory mechanical work rate was the same as in the normal subjects (Fig. 2, right). Diminished sensitivity appeared to be dominant in reducing ventilatory response to $\mathrm{CO}_{2}$ in these subjects. In Fig. 3, three further patients are shown in whom there was both a reduction in inspiratory mechanical work rate response to $\mathrm{CO}_{2}$ (Fig. 3, left) and a reduction in the ventilation achieved for a given increment in inspiratory mechanical work (Fig. 3, right). Both mechanical factors and diminished sensitivity appeared to be important in reducing ventilatory response to $\mathrm{CO}_{2}$ in these patients.

Details of the correlations between the clinical features and the $\mathrm{CO}_{2}$ response findings are given in Table IV. The significant positive correlations

\section{T A B L E I V}

CORRELATION OF CLINICAL FEATURES, INVESTIGATIONS, AND BLOOD GASES WITH SLOPES OF RESPONSE

\begin{tabular}{|c|c|c|c|}
\hline \\
\hline & SW்i/POO, & $\mathbf{S W} \mathbf{W} / \dot{V}_{\mathbf{B}}$ & SVE/POO, \\
\hline $\begin{array}{ll}\text { Dyspnoea } & 3: 2 \\
& 2: 1 \\
& 3: 1 \\
& \\
\text { Oedema } & \end{array}$ & \begin{tabular}{|c|}
$0.01<P<0.02$ \\
N.S. \\
$0.01<P<0.02$ \\
Positive \\
$0.02<P<0.05$ \\
Negative
\end{tabular} & $\begin{array}{c}\text { N.S. } \\
\text { N.S. } \\
0.005<P<0.01 \\
\text { Positive } \\
\text { N.S. }\end{array}$ & $\begin{array}{c}0.02<P<0.05 \\
\text { N.S. } \\
\text { N.S. } \\
\text { Positive } \\
0.005<P<0.01 \\
\text { Negative }\end{array}$ \\
\hline $\begin{array}{l}\text { Sputum } \\
\text { mucopurulent } \\
\text { Polycythaemia }\end{array}$ & $\begin{array}{c}\text { N.S. } \\
0.02<P<0.05 \\
\text { Negative }\end{array}$ & $\begin{array}{l}\text { N.S. } \\
\text { N.S. }\end{array}$ & N.S. \\
\hline $\begin{array}{l}\text { Right } \\
\text { ventricular } \\
\text { hypertrophy } \\
\text { Emphysema }\end{array}$ & $\begin{array}{c}\text { N.S. } \\
\begin{array}{c}0.02<\text { P }<0.05 \\
\text { Positive }\end{array}\end{array}$ & $\begin{array}{l}\text { N.S. } \\
\text { N.S. }\end{array}$ & $\begin{array}{l}\text { N.S. } \\
\text { N.S. }\end{array}$ \\
\hline $\begin{array}{l}\text { TLC } \\
\text { PaCo, }\end{array}$ & $\begin{array}{c}\text { N.S. } \\
0.02<P<0.05 \\
\text { Negative }\end{array}$ & N.S. & $\begin{array}{l}\text { N.S. } \\
\text { N.S. }\end{array}$ \\
\hline $\mathrm{SaO}_{2}$ & & N.S. & N.S. \\
\hline
\end{tabular}

to emerge were between the slopes of the $\dot{\mathrm{W}}_{\mathrm{I}} / \mathrm{PCO}_{2}$ relation and the presence of dyspnoea and radiographic evidence of emphysema; significant negative correlations appeared between this slope and oedema, polycythaemia and resting $\mathrm{PaCO}_{2}$. The slopes of the $\mathrm{V}_{E} / \mathbf{P C O}_{2}$ relations were correlated with dyspnoea and oedema and the slopes of the $\dot{W}_{I} / \vec{V}_{\mathbf{B}}$ relations with dyspnoea alone. Neither of these slopes was correlated with any of the other 


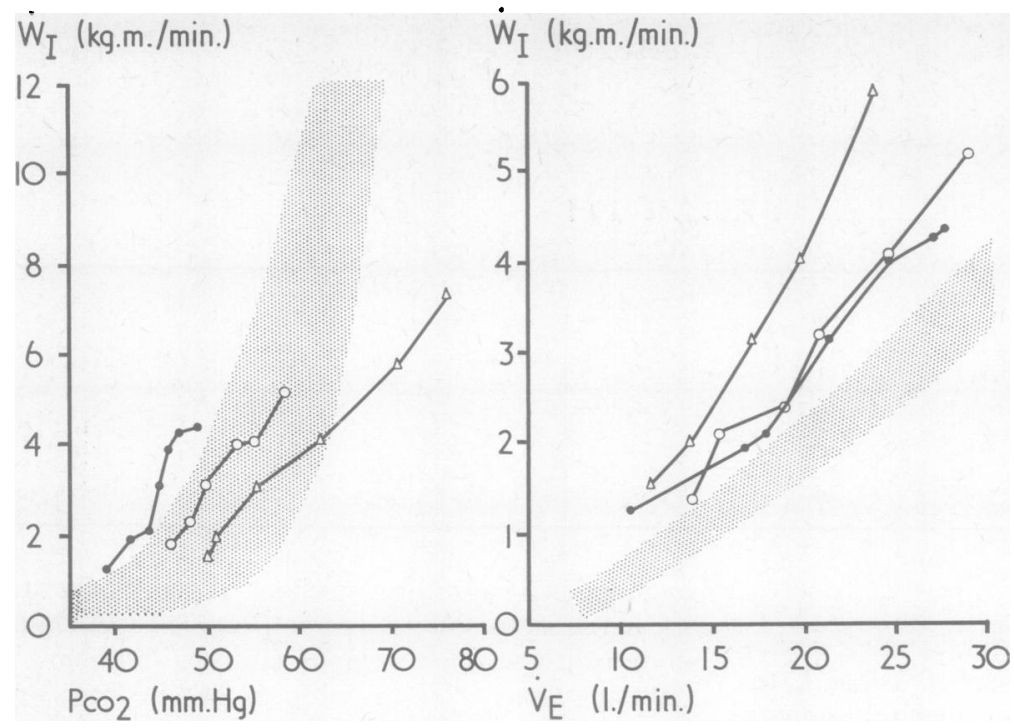

FIG. 1. Inspiratory mechanical work rate $\left(\dot{W}_{\mathrm{I}}\right)$ responses of three patients (W.E. $\triangle$; J.Br. O; F.D. -) in whom $\mathrm{CO}_{2}$ sensitivity is relatively normal (left) but the ventilation $\left(\dot{\mathrm{V}}_{\mathrm{E}}\right)$ achieved for a given increment in mechanical work is less than normal (right).

FIG. 2. Inspiratory mechanical work rate $\left(\dot{W}_{I}\right)$ responses of three patients (S.S. $\triangle$; S.R. O; J.F.๑) in whom there is severe loss of sensitivity (left) although the ventilation $\left(\dot{\mathbf{V}}_{\mathrm{E}}\right)$ achieved for a given increment in mechanical work is normal (right).
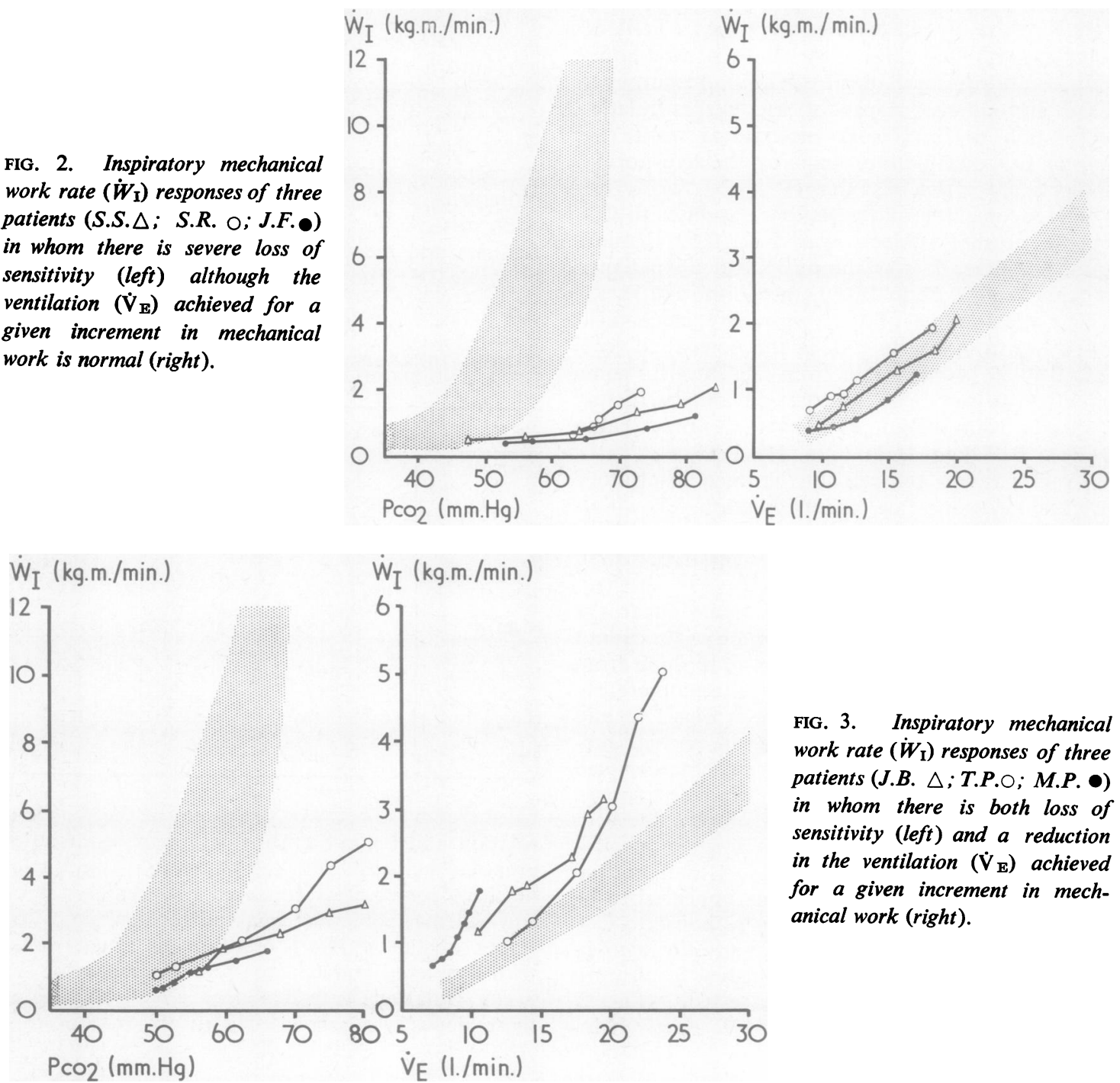

FIG. 3. Inspiratory mechanical work rate $\left(\dot{W}_{\mathrm{I}}\right)$ responses of three patients (J.B. $\triangle$; T.P.O; M.P. ๑) in whom there is both loss of sensitivity (left) and a reduction in the ventilation $\left(\dot{\mathrm{V}}_{\mathrm{E}}\right)$ achieved for a given increment in mech. anical work (right). 
features assessed. The correlations for dyspnoea were such that patients with the most severe grade of dyspnoea responded best to $\mathrm{CO}_{2}$ both in terms of inspiratory mechanical work and ventilation and also that they worked hardest for a given level of ventilation.

\section{DISCUSSION}

RESPONSES TO $\mathrm{CO}_{2}$ Diminished ventilatory response to $\mathrm{CO}_{2}$ in patients with chronic obstructive airways was first recorded by Reinhardt (1912), although credit for this is usually given to Scott (1920). These early observations were confirmed by subsequent workers. Scott (1920) considered that the increased buffering capacity of the blood consequent upon renal compensation for respiratory acidosis was an adequate explanation, but the two explanations which have been considered most likely are mechanical hindrance and impaired respiratory centre sensitivity. The main evidence in favour of the former is the observation that the ventilatory response to $\mathrm{CO}_{2}$ can be reduced in normals by the introduction of a viscous resistance at the mouth (Cherniack and Snidal, 1956). This very observation, however, makes the assessment of respiratory centre sensitivity in terms of a ventilatory response to $\mathrm{CO}_{2}$ meaningless. For this reason attempts have been made to assess the output of the respiratory centre in terms of some intermediate response, such as mechanical work, oxygen consumption or respiratory muscle electromyogram. It follows that the relationship between this output and the ventilation achieved will be an expression of the impedance to ventilation due to mechanical factors within the lungs and bronchi.

In normals, Eldridge and Davis (1959) and Milic-Emili and Tyler (1963) measured the mechanical work done against the viscous resistances of the lungs and the elastic resistances of the lung and chest wall with and without added viscous resistances. The latter workers found that $\mathrm{CO}_{2}$ responses in terms of mechanical work done during inspiration did not alter from control values in the presence of added viscous resistances sufficient to reduce the ventilatory response to $50 \%$ of control values.

In patients, Fritts, Fishman, and Cournand (1957), also measuring mechanical work, found the response to $\mathrm{CO}_{2}$ in four emphysematous subjects to be normal. Richards et al. (1958), measuring the oxygen consumption for the increased ventilation in nine emphysematous subiects with $\mathrm{CO}_{2}$ retention, likewise concluded that the response was little different from that in normals. The ventilation achieved for a given increment in oxygen consumption was, however, much less than normal in the emphysematous group. The conclusion drawn from these observations was that diminished ventilatory response to $\mathrm{CO}_{2}$ was due to mechanical factors.

Brodovsky et al. (1960) repeated the observations on oxygen consumption but at the same time measured the mechanical efficiency of the respiratory muscles and so were able to estimate the total mechanical work done by them. They found that the total mechanical work response to $\mathrm{CO}_{2}$ was reduced in nine patients with emphysema, compared with eight normal subjects, and that this was associated with reduced efficiency. This implies that respiratory centre output is normal and that the reduced efficiency may be responsible for the diminished total mechanical work and ventilatory responses to $\mathrm{CO}_{2}$. Fritts, Filler, Fishman, and Cournand (1959) had, on the other hand, found mechanical efficiency during voluntary hyperventilation to be very little different in six patients with emphysema compared with seven normals. This discrepancy is probably attributable to different methods of measurement.

Studies of inspiratory mechanical work rate response to $\mathrm{CO}_{2}$ have recently been reported by Flenley and Millar (1968). They found a diminished response in six out of eight bronchitic patients with chronic ventilatory failure and a normal response in the other two. No correlations between clinical features and $\mathrm{CO}_{2}$ response were made in this or in previously reported studies. However, an association with clinical features was noted by Lourenço and Miranda (1968). They have recently reported a study in which the output from the respiratory centre was assessed in terms of the integrated electromyogram of the diaphragm during $\mathrm{CO}_{2}$ stimulation by rebreathing. They were able to divide their patients into two groups, one showing a diminished drive and the other showing a normal or increased drive. This division was related to the presence of features suggesting respectively the bronchitic and emphysematous types of patient.

In the present study the motor output of the respiratory centre was assessed in terms of work done on the lungs and chest wall by the inspiratory muscles. We did not attempt to measure the efficiency of the respiratory muscles and therefore cannot with complete confidence relate mechanical work response to respiratory centre output. However, we believe it unlikely that the finding of a diminished inspiratory mechanical work rate 
response to $\mathrm{CO}_{2}$ in certain patients is due to reduced efficiency for the following reasons. First, the only subjects in whom Fritts et al. (1959) conclusively demonstrated diminished efficiency were obese patients with a body weight of more than $120 \mathrm{~kg}$. None of our patients showed this degree of obesity. Secondly, the disadvantage of working at a high total lung capacity which might be expected to reduce mechanical efficiency is found in patients with high, rather than low, inspiratory mechanical work rate responses to $\mathrm{CO}_{2}$ (see Tables I and II). Finally, Brodovsky et al. (1960) showed that when ventilatory response to $\mathrm{CO}_{2}$ was diminished in normal subjects by the interposition of an added viscous resistance, the total mechanical work response to $\mathrm{CO}_{2}$ remained constant although the oxygen consumption response increased. It seemed unlikely that $\mathrm{CO}_{2}$ sensitivity could be abruptly altered, and they therefore suggested 'that incremental changes in total mechanical work are a more accurate gauge of the response of the respiratory apparatus to carbon dioxide than are increments of ventilation or oxygen consumption'. Taking into consideration as well the observations of Milic-Emili and Tyler (1963) on the correlation of inspiratory as opposed to expiratory or total mechanical work rate with $\mathrm{CO}_{2}$ tension, we shall therefore hereafter interpret diminished inspiratory mechanical work rate. response to $\mathrm{CO}_{2}$ as evidence for diminished sensitivity.

POSSIBLE CAUSES OF LOSS OF $\mathrm{CO}_{2}$ SENSITIVITY. On the basis of animal experiments which have shown that hyperoxia abolishes the peripheral chemoreceptor responses to hypercapnia (Neil and Joels, 1963 ; Bouverot, Flandrois, Puccinelli, and Dejours, 1965), the sensitivity being assessed should be that of the central chemoreceptors. The inspired oxygen concentration was $100 \%$ at the onset of the rebreathing procedure and never less than $40 \%\left(\mathrm{P}_{\mathrm{I}} \mathrm{O}_{2}\right.$ of $280 \mathrm{~mm}$. $\left.\mathrm{Hg}\right)$ at the end.

The factors responsible for diminution in central $\mathrm{CO}_{2}$ sensitivity have not been elucidated. Increased buffering associated with metabolic compensation for raised $\mathrm{PCO}_{2}$ has been suggested as one factor (Scott, 1920 ; Tenney, 1954). However, this cannot be the major factor because reduced ventilatory responses to $\mathrm{CO}_{2}$ are seen in the absence of $\mathrm{CO}_{2}$ retention and because, even when present, the increased buffering is unable to prevent a considerable rise in arterial $\left[\mathrm{H}^{+}\right]$on acute exposure to $\mathrm{CO}_{2}$ (Flenley and Millar, 1967). Investigation of this problem at a cellular level has been undertaken by Adler, Roy, and Relman (1965), who related $\left[\mathrm{H}^{+}\right]$changes within muscle cells in vitro to changes in external $\mathrm{PCO}_{2}$ and bicarbonate. At high extracellular bicarbonate levels, intracellular $\left[\mathrm{H}^{+}\right]$change in response to a given increment in extracellular $\mathrm{PCO}_{2}$ was certainly less than at normal levels of extracellular bicarbonate, but the effect was small. Neuronal cellular behaviour in the intact subject may, however, be entirely different. Recently measurements of cerebrospinal fluid (C.S.F.) acid-base state have been held to reflect changes in the environment of respiratory centre neurones (Fencl, Miller, and Pappenheimer, 1966). Our measurements of C.S.F. acid-base state in these patients did not suggest any basic difference between the responses of the two clinical extremes to chronic hypercapnia, although no assessment of C.S.F. response to acute hypercapnia was possible (Lane, Howell, and Stretton, in preparation).

Increased buffering has been studied in relation to $\mathrm{CO}_{2}$ responsiveness in normal human subjects. The administration of oral bicarbonate will raise the threshold for $\mathrm{CO}_{2}$ stimulation, but the slope of the ventilatory response to $\mathrm{CO}_{2}$ is unaltered (Katsaros, Loeschcke, Lerche, Schönthal, and Hahn, 1960). If, on the other hand, normal subjects are exposed to an environment rich in $\mathrm{CO}_{2}$ for periods of up to three weeks, the slope of the ventilatory response to $\mathrm{CO}_{2}$ is reduced (Schaefer, 1958). This effect could exaggerate any state of reduced $\mathrm{CO}_{2}$ sensitivity in the patients studied but would not explain how the mechanism is initiated.

A study of the interaction of $\mathrm{CO}_{2}$ with other ventilatory control mechanisms may offer clues. Flenley and Millar (1967) examined ventilatory responses to oxygen and carbon dioxide in patients with chronic respiratory failure due to airways obstruction and suggested insensitivity to hypoxia as well as to hypercapnia in some patients. Since hypoxia is normally thought to increase $\mathrm{CO}_{2}$ sensitivity (Lloyd, Jukes, and Cunningham, 1958), a diminished hypoxic sensitivity may abolish this positive interaction. Jones (1966) also implicated reduced hypoxic sensitivity in bronchitic as opposed to emphysematous patients to explain differences in the behaviour of the two groups when exercised.

The positive interaction of neurogenic factors with $\mathrm{CO}_{2}$ responsiveness was demonstrated in anaesthetized rabbits by Scott (1908) and in unanaesthetized rabbits by Richardson and Widdicombe (1969). Observations in unanaesthetized human subjects are confined to those on one individual (Guz, Noble, Widdicombe, Trenchard, and Mushin, 1966). Ventilatory response to $\mathrm{CO}_{2}$ was 
shown to be diminished after local anaesthetic block of the vagus and glossopharyngeal nerves in the neck. These observations suggest that vagal impulses from the lungs are important in the maintenance of $\mathrm{CO}_{2}$ sensitivity. It is therefore possible that lung damage, such as may occur in severe chronic bronchitis, may interfere with afferent vagal discharges and so diminish central sensitivity to $\mathrm{CO}_{2}$.

RELATION OF CLINICAL FEATURES TO $\mathrm{CO}_{2}$ SENSITIVIrY The most significant correlation to emerge from the analysis of the clinical features was that between dyspnoea and $\mathrm{CO}_{2}$ sensitivity. Patients with a grossly diminished $\mathrm{CO}_{2}$ sensitivity were relatively untroubled by dyspnoea. There seems little doubt that mechanisms exist within the lungs and chest wall which are capable of detecting an added load such as that created by airways obstruction and that such mechanisms contribute towards the sensation of dyspnoea. With any given degree of obstruction, however, the patient will be more or less aware of the added load according to the varying level of ventilatory drive. It appears that in certain patients reduced sensitivity to $\mathrm{CO}_{2}$ removes such a powerful ventilatory drive that dyspnoea becomes a relatively unimportant symptom. Such patients may well remain in gainful occupation despite a level of airways obstruction represented by an $\mathrm{FEV}_{1.0}$ of 0.7 to 0.81 ., whilst others in whom $\mathrm{CO}_{2}$ sensitivity remains normal are house-bound at a similar level of $\mathrm{FEV}_{1 \cdot 0}$. In the latter patients mechanical factors are of great importance. This emerges from the correlation found between the slope of $\dot{w_{I}} / \nabla_{B}$ curves and the level of dyspnoea, which signifies that those patients who worked hardest for a given level of ventilation experienced most dyspnoea. Clearly both the degree of retention of $\mathrm{CO}_{2}$ sensitivity and the severity of airways obstruction were important factors in the genesis of dyspnoea in this group of patients. Other factors, such as anoxic or neurogenic drives or psychological disturbance, may have played some part in certain patients but would appear not to have been of dominant importance in the group as a whole.

The interplay between mechanical factors and $\mathrm{CO}_{2}$ sensitivity is also important in determining the resting level of arterial $\mathrm{PCO}_{2}$, although again other ventilatory drives may also be involved. This has been examined by Lane, Howell, and Giblin (1968), who showed that, in patients with a normal $\mathrm{CO}_{2}$ sensitivity, resting $\mathrm{PaCO}_{2}$ remained within normal limits down to a level of airways obstruction represented by an $\mathrm{FEV}_{1 \cdot 0}$ of about 0.5 litre. By contrast, patients with a greatly diminished $\mathrm{CO}_{2}$ sensitivity showed a rise in arterial $\mathrm{PCO}_{2}$ when the $\mathrm{FEV}_{1 \cdot 0}$ was of the order of 1.1 to 1.2 litres. In the present study, sufficient of the patients had a similar $\mathrm{FEV}_{1 \cdot 0}$ of around $0.6-0.8$ litre to allow a positive correlation between $\mathrm{CO}_{2}$ sensitivity and resting $\mathrm{PaCO}_{2}$ to emerge.

A contrast between patients in terms of dyspnoea and resting $\mathrm{PaCO}_{2}$ begins to suggest the contrast between the 'pink and puffing' emphysematous subject and the 'blue and bloated' bronchitic patient. This comparison is further supported by the significant correlations found between chest radiographic evidence of emphysema and retention of $\mathrm{CO}_{2}$ sensitivity, and the presence of oedema and diminished $\mathrm{CO}_{2}$ sensitivity. It would appear, therefore, that at least four of the features listed in the clinically contrasting groups were significantly associated with $\mathrm{CO}_{2}$ sensitivity. This association was also noted by Lourenço and Miranda (1968) using the diaphragmatic electromyogram as the index of respiratory centre output.

No positive correlation emerged between arterial saturation and $\mathrm{CO}_{2}$ sensitivity, although polycythaemia, which is generally thought to be secondary to chronic hypoxia, was seen significantly more often in patients with a reduced sensitivity to $\mathrm{CO}_{2}$. Whilst reduced $\mathrm{CO}_{2}$ sensitivity is associated with a raised $\mathrm{PCO}_{2}$ (arterial and alveolar) and therefore a reduced alveolar $\mathrm{Po}_{2}$, other factors, such as ventilation/perfusion inequalities, determine the alveolar/arterial $\mathrm{Po}_{2}$ gradient and so the level of arterial oxygenation. The dominant importance of such factors in many patients allows the recognition of that common clinical presentation of a 'blue and puffing' bronchitic. In these instances ventilation/perfusion inequalities contribute towards the desaturation, whilst the presence of considerable ventilatory drive causes the dyspnoea. An anoxic drive may well be of importance in these patients.

None of the other clinical features examined correlated with $\mathrm{CO}_{2}$ sensitivity, and correlations with the slope of the $\dot{W}_{I} / \vec{V}_{E}$ curve or the ventilatory response to $\mathrm{CO}_{2}$ were seen only in the instances of dyspnoea and oedema. The correlation between dyspnoea and the $\dot{\mathrm{W}}_{\mathrm{I}} / \overrightarrow{\mathrm{V}}_{\mathrm{E}}$ slope has already been discussed. Ventilatory response to $\mathrm{CO}_{2}$ was positively correlated with dyspnoea. This suggests that in this group of patients diminished respiratory drive was more important in producing the diminished ventilatory response to $\mathrm{CO}_{2}$ than mechanical factors, since in the latter 
instance a reduced ventilatory response would be associated with increased dyspnoea. For oedema the correlation was with the ventilatory response to $\mathrm{CO}_{2}$ : the clinical significance of this finding is not apparent. Clinical features in chronic airways obstruction were also examined by Clark (1968), who found no relation between clinical type, as expressed by the divisions bronchitic, emphysematous, and intermediate (Burrows et al., 1966), and ventilatory response to $\mathrm{CO}_{2}$.

It is possible from the above analysis to group together five features significantly correlated with diminished $\mathrm{CO}_{2}$ sensitivity, viz., a relative lack of dyspnoea, oedema, polycythaemia, a raised resting arterial $\mathrm{PCO}_{2}$ and the absence of emphysema on the chest radiograph. The concurrence of four or five of these features in a patient with severe or moderately severe chronic airways obstruction would constitute good circumstantial evidence for diminished $\mathrm{CO}_{2}$ sensitivity. The complete clinical picture presented by these patients is, however, determined by a complex interaction of several pathological processes. This study has highlighted the place of one of these processes, $\mathrm{CO}_{2}$ sensitivity, and indicated the importance of other ventilatory drives, the level of airways obstruction and the degree of ventilation/perfusion equality.

In the aetiology of the distinction between patients who are of the 'blue and bloated' bronchitic type rather than of the 'pink and puffing' emphysematous type, loss of sensitivity to $\mathrm{CO}_{2}$ would seem to be one of the more important factors. It seems likely, however, that in individual patients several other processes contribute towards the overall clinical picture, and the investigation of these is likely to lead to a better understanding of the pathophysiology of chronic airways obstruction.

We wish to thank Professor D. A. K. Black, Dr. C. S. D. Don, Dr. H. Howat, and Dr. S. Lal for permission to study patients under their care. The skilled technical assistance of Mrs. B. Giblin is gratefully acknowledged. One of us (D. J. L.) was supported by a research grant from the Board of Governors of the Manchester Royal Infirmary.

\section{REFERENCES}

Adler, S., Roy, A., and Relman, A. S. (1965). Intracellular acidbase regulation. I. The response of muscle cells to changes in $\mathrm{CO}_{2}$ tension or extra cellular bicarbonate concentration. II. The interaction between $\mathrm{CO}_{2}$ tension and extracellular bicarbonate in the determination of muscle cell $\mathrm{pH}$. J. clin. Invest., 44, 8

Alexander, J. K., West, J. R., Wood, J. A., and Richards, D. W. (1955) Analysis of respiratory response to carbon dioxide inhalation in varying clinical states of hypercapnia, anoxia, and acid-base derangement. Ibid., 34, 511 .

Baldwin, E. deF., Cournand, A., and Richards, D. W. (1949). Pulmonary insufficiency. III. A study of 122 cases of chronic pulmonary emphysema. Medicine (Baltimore), 28, 201.
Bouverot, P., Flandrois, R., Puccinelli, R., and Dejours, P. (1965). Étude du role des chémorécepteurs artériels dans la régulation de la respiration pulmonaire chez la chien éveillé. Arch. int. Pharmacodyn., 157, 253.

Briscoe, W. A., and Nash, E. S. (1965). The slow space in chronic $\overline{\bar{D}}$ obstructive pulmonary disease. Ann. N.Y. Acad. Sci., 121, 706 .

Brodovsky, D., Macdonell, J. A., and Cherniack, R. M. (1960). ○ The respiratory response to carbon dioxide in health and emphysema. J. clin. Invest., 39, 724.

Burrows, B., Fletcher, C. M., Heard, B. E., Jones, N. L., and Wootliff, J. S. (1966). The emphysematous and bronchial types of $O$ chronic airways obstruction. Lancet, 1, 830.

Campbell, E. J. M. (1958). The Respiratory Muscles and the Mechanics $\vec{\omega}$ of Breathing. Lloyd-Luke, London.

Cherniack, R. M., and Brown, E. (1965). A simple method for measuring total respiratory compliance: normal values for males. $\vec{x}$ J. appl. Physiol., 20,87.

and Snidal, D. P. (1956). The effect of obstruction to breathing $N$ on the ventilatory response to $\mathrm{CO}_{2}$. J. clin. Invest., 35, 1286.

Clark, T. J. H. (1968). The ventilatory response to $\mathrm{CO}_{2}$ in chronic $N$ airways obstruction measured by a rebreathing method. Clin. $\vec{G}$ Sci., 34, 559.

Donald, K. W., and Christie, R. V. (1949). The respiratory response 0 to carbon dioxide and anoxia in emphysema. Ibid., 8, 33.

Eldridge, F., and Davis, J. M. (1959). Effect of mechanical factors on respiratory work and ventilatory responses to carbon dioxide. J. appl. Physiol., 14, 721.

Fencl, V., Miller, T. B., and Pappenheimer, J. R. (1966). Studies on the respiratory response to disturbances of acid-base balance, $\frac{\rho}{\partial}$ with deductions concerning the ionic composition of cerebral interstitial fluid. Amer. J. Physiol., 210, 459.

Filley, G. F., Beckwitt, H. J., Reeves, J. T., and Mitchell, R. S. (1968). Chronic obstructive bronchopulmonary disease. II. Oxygen transport in two clinical types. Amer. J. Med., 44, 26.

Fishman, A. P., Samet, P., and Cournand, A. (1955). Ventilatory drive in chronic pulmonary emphysema. Ibid., 19, 533.

Flenley, D. C., and Millar, J. S. (1967). Ventilatory response to oxygen and carbon dioxide in chronic respiratory failure. Clin. Sci., 33, 319.

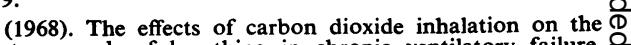
inspiratory work of breathing in chronic ventilatory failure. Ibid., 34, 385.

Fletcher, C. M., Hugh-Jones, P., McNicol, M. W., and Pride, N. B. (1963). The diagnosis of pulmonary emphysema in the presence of chronic bronchitis. Quart. J. Med., 32, 33.

Fritts, H. W., Filler, J., Fishman, A. P., and Cournand, A. (1959). The efficiency of ventilation during voluntary hyperpnea:studies in normal subjects and in dyspneic patients with either chronic pulmonary emphysema or obesity. J. clin. Invest., 38, 1339.

- Fishman, A. P., and Cournand, A. (1957). Factors contri- $\triangle$ buting to the diminished ventilatory response of $\mathrm{CO}_{2}$ of patients $\mathrm{C}$ with obstructive emphysema. Fed. Proc., 16, 41

Guz, A. Noble, M. I. M., Widdicombe, J. G., Trenchard, D., and Mushin, W. W. (1966). The effect of bilateral block of vagus 0 and glossopharyngeal nerves on the ventilatory response of $\mathrm{CO}_{2}$ of conscious man. Resp. Physiol., 1, 206.

Howell, J. B. L., and Campbell, E. J. M. (Editors) (1966). Breathless-음 ness in pulmonary disease. In Breathlessness: Proceedings of an International Symposium. p. 165. Blackwell, Oxford.

and Lane, D. L. (1969). Hypercapnia in pulmonary disease. 윽 J. Physiol. (Lond.), 202, $8 P$.

Jones, N. L. (1966). Pulmonary gas exchange during exercise in $N$ patients with chronic airway obstruction. Clin. Sci., 31, 39.

Kahana, L. M., Aronovitch, M., and Place, R. (1963). A comparative N study of the clinical and functional pattern in emphysematous patients with and without respiratory failure. Amer. Rev. resp. N Dis., 87, 699 .

Katsaros, B., Loeschcke, H. H., Lerche, D., Schönthal, H., and Hahn, N. (1960). Effect of bicarbonate alkalosis on pulmonary ventilation in man. Determination of the partial effects of pHe and $\mathrm{CO}$. pressure on the ventilation and comparison with the results in acidosis. Pflügers Arch. ges. Physiol., 271, 732.

Lane, D. J., Howell, J. B. L., and Giblin, B. (1968). Relation between? airways obstruction and $\mathrm{CO}_{2}$ tension in chronic obstructive $T$ airways disease. Brit. med. J., 3,707 .

Laws, J. W., and Heard, B. E. (1962). Emphysema and the chest film: a retrospective radiological and pathological study. Brit. J. Radiol., 35, 750.

Lloyd, B. B., Jukes, M. G. M., and Cunningham, D. J. C. (1958) The relation between alveolar oxygen pressure and the respi43, 214. 
Loureņ̧o, R. V., and Miranda, J. M. (1968). Drive and performance of the ventilatory apparatus in chronic obstructive lung disease. New Engl. J. Med., 279, 53.

Milic-Emili, J., and Tyler, J. M. (1963). Relation between work output of respiratory muscles and end-tidal $\mathrm{CO}_{2}$ tension. J. appl. Physiol., 18, 497.

Mitchell, R. S., and Filley, G. F. (1964). Chronic obstructive bronchopulmonary disease. 1. Clinical features. Amer. Rev. resp. Dis., 89, 360.

Medical Research Council (1966). Questionnaire on respiratory symptoms. Forms and instructions distributed by $\mathbf{W}$. J. Holman, Ltd., Dawlish, Devon.

Neil.E., and Joels, N. (1963). The carotid glomus sensory mechanism. In The Regulation of Human Respiration. Ed. Cunningham, D. J. C., and Lloyd, B. B. Blackwell, Oxford.

Ogilvie, C. (1959). Patterns of disturbed lung function in patients with chronic obstructive vesicular emphysema. Thorax, 14, 113 .

Otis, A. B. (1964). The work of breathing. In Handbook of Physiology, Section 3: Respiration, vol. 1, Chapter 17. American Physiological Society, Washington.

Park, S. S. (1965). Factors responsible for carbon dioxide retention in chronic obstructive lung disease. Amer. Rev. resp. Dis., 92, 245.

Prime, F. J., and Westlake, E. K. (1954). The respiratory response to $\mathrm{CO}_{2}$ in emphysema. Clin. Sci., 13, 321 .

Rahn, H., Otis, A. B., Chadwick, L. E., and Fenn, W. O. (1946). The pressure-volume diagram of the thorax and lung. Amer. J. Physiol., 146, 161.
Reinhardt, R. (1912). Uber das Verhältnis von $\mathrm{CO}_{\boldsymbol{\gamma}}$-Ausscheidung zur Atemgrösse beim Lungenemphysem. Dtsch. Arch. klin. Med., 109, 192.

Richards, D. W. (1960). Pulmonary emphysema; etiologic factors and clinical forms. Ann. intern. Med., 53, 1105.

- Fritts, H. W., Jr., and Davis, A. L. (1958). Observations on the control of respiration in emphysema: the effects of oxygen on ventilatory response to $\mathrm{CO}$, inhalation. Trans. Ass. Amer. Phycns, 71, 142.

Richardson, P. S., and Widdicombe, J. G. (1969). The role of vagus nerves in the ventilatory responses to hypercapnia and hypoxia in anaesthetized and unanaesthetized rabbits. Resp. Physiol., $7,122$.

Robin, E. D., and O'Neill, R. P. (1963). The fighter versus the nonfighter. Control of ventilation in chronic obstructive pulmonary disease. Arch. Environ. Hlth, 7, 125.

Scadding, J. G. (1963). Meaning of diagnostic terms in bronchopulmonary disease. Brit. med. J., 2, 1425.

Schaefer, K. E. (1958). Respiratory pattern and respiratory response to CO. J. appl. Physiol., 13, 1.

Scott, F. H. (1908). On the relative parts played by nervous and chemical factors in the regulation of respiration. J. Physiol. (Lond.), 37, 301.

Scott, R. W. (1920). Observations on the pathologic physiology of chronic pulmonary emphysema. Arch. intern. Med., 26, 544.

Tenney, S. M. (1954). Ventilatory response to carbon dioxide in pulmonary emphysema. J. appl. Physiol., 6, 477. 